\title{
Instituições e desenvolvimento econômico: uma nota crítica ao "nacionalismo metodológico"
}

\author{
Carlos Aguiar de Medeiros ${ }^{1}$
}

\section{Resumo}

$\mathrm{Na}$ presente nota argumenta-se que interpretações predominantes sobre as diferentes trajetórias nacionais de desenvolvimento assumem um "nacionalismo metodológico" em que as trajetórias dos países são explicadas essencialmente por estratégias implementadas por seus estados nacionais. Estes em geral são concebidos como entidades relativamente autônomas dos interesses materiais e das relações inter-estatais. Após uma breve descrição da evolução destas interpretações identificam-se alguns de seus limites.

Palavras-chave: Instituições; Desenvolvimento econômico; Relações externas.

\begin{abstract}
Most historical explanations of national development experiences assume a "methodological nationalism" approach whereas different national performances are basically explained by State strategies. Developmental States are generally conceptualized as an autonomous entity distant from material interests and inter state political pressures. After a short description of these approaches some limits are considered in this note.
\end{abstract}

Key words: Institutions; Economic development; External relations.

JEL B52, O43, O54.

Tendo em vista a crescente divergência no desenvolvimento econômico dos países ocorrida nas últimas décadas, a literatura contemporânea predominante sobre o desenvolvimento econômico tem se concentrado basicamente nas explanações sobre as distintas trajetórias nacionais de desenvolvimento, na busca de algumas redefinições sobre o subdesenvolvimento e na elaboração de proposições normativas para os países mais pobres. Nas explanações do mainstream atual sobre a divergência entre países há duas abordagens principais (não necessariamente compatíveis): na primeira predominam análises baseadas em estudos econométricos sobre algumas variáveis escolhidas a partir de algum referencial de causalidade neoclássico ${ }^{2}$ e na segunda estudos históricos comparativos sobre experiências nacionais privilegiando a qualidade das instituições como fator diferenciador principal. ${ }^{3}$ Os estudos normativos seguem em geral este mesmo referencial institucionalista, buscando incorporar novas dimensões e redefinições conceituais sobre o desenvolvimento tendo por eixo os indivíduos e suas capacitações.

(1) Professor associado do Instituto de Economia da Universidade Federal do Rio de Janeiro (IE/UFRJ) / Bolsista do CNPq, Rio de Janeiro, RJ, Brasil. Agradeço (sem implicar nas conclusões) as observações de Ricardo Carneiro (IE/Unicamp).

(2) Uma síntese crítica destes estudos encontra-se em Ross (2001).

(3) A referência fundamental é North (1990). 
Estes estudos concluem em geral com a formulação de proposições para os países mais pobres como a provisão de micro-finanças de forma a ajudar os indivíduos pobres a saírem por si próprios da pobreza, etc. ${ }^{4}$

São diversas as escolas e contribuições divergentes desta abordagem predominante tanto no plano teórico quanto nas explanações sobre as trajetórias nacionais. Como observou Ha-Joon Chang (2009), o que esta abordagem possui de mais geral é a desconsideração da produção e, consequentemente, da industrialização, enquanto processo decisivo e diferenciador da riqueza das nações. Com efeito, a despeito de diversas contribuições que distinguem os modernos institucionalistas do mainstream do pensamento neoclássico convencional, há um ponto de convergência central, a localização do problema econômico fundamental no processo de troca e nas decisões individuais, em ampla divergência com a abordagem dos economistas políticos clássicos centrados na produção e nas suas instituições. ${ }^{5}$

Desta outra perspectiva, autores de um amplo espectro metodológico não neoclássico descrevem o desenvolvimento nacional - seguindo uma direção iniciada por William Petty e que no pós-guerra ganhou extraordinária expansão nos trabalhos dos Pioneiros do Desenvolvimento ${ }^{6}$ - como um processo de mudança na estrutura produtiva, na tecnologia e nas instituições e em particular na problemática específica da industrialização como fator diferenciador das trajetórias nacionais. Esta abordagem enfatiza a importância da acumulação de capital, a natureza não mecânica do progresso tecnológico, a importância central do Estado e das instituições na elaboração de estratégias nacionais e na coordenação dos investimentos. ${ }^{7}$

O objetivo da presente nota é identificar alguns limites e lacunas presentes em grande parte desta literatura. ${ }^{8}$ Há em boa parte dos estudos críticos ao mainstream um predomínio do que Gore (1996) denominou de nacionalismo metodológico. Buscando aqui uma similitude com o individualismo metodológico, típico da economia neoclássica, a nação é referida nestes estudos como unidade auto-suficiente e inserida num ambiente internacional indiferenciado: “...o objeto da investigação é frequentemente o desempenho econômico e social de um país, usualmente em comparação com outros países. Os desempenhos específicos são tipicamente explicados dividindo os fatores causais em fatores internos e externos, e então o que ocorre num determinado país ou ao conjunto de países de uma determinada região do mundo é atribuído aos fatores internos" (Gore, 1996, p. 5). ${ }^{9}$

(4) Como, por exemplo nos Objetivos do Desenvolvimento do Milênio patrocinado pelas Nações Unidas.

(5) Para uma discussão deste ponto, ver Pasinetti (2007).

(6) No Brasil uma coleção clássica sobre contribuições destes autores é a de Agarwalla e Singh (1969).

(7) Como na tradição que vai de Alexande Gershenkron às descrições de trajetórias como nos diversos trabalhos institucionalistas sobre o desenvolvimento asiático. Para uma coletânea, ver Chang (2007).

(8) É evidente que num esforço de síntese da literatura do desenvolvimento sempre se incorre em excessiva simplificação, diversos trabalhos relevantes não se encaixam necessariamente nos esquemas analíticos aqui considerados. Estes, entretanto, descrevem uma forma de pensamento predominante nestes estudos.

(9) Gore tinha em vista neste artigo as insuficiências das explanações correntes sobre a diferenciação das trajetórias latino-americanas e asiáticas desde os anos 1980. Nesta direção ver Medeiros (1997). 
Ainda que existam importantes exceções, dois desdobramentos seguem desta abordagem. Em primeiro lugar, não raro nestes estudos, em particular na literatura institucionalista heterodoxa sobre a industrialização asiática, a análise do processo de mudança estrutural e das estratégias de desenvolvimento é articulada com as dimensões macroeconômicas (em geral confinadas ao curto prazo), conferindo-se pouca ênfase na demanda efetiva (em economias abertas) para as trajetórias de desenvolvimento. Em segundo lugar, na discussão sobre o papel central do Estado nas experiências de industrialização, dificilmente se discute por que o Estado cumpre ou por que não cumpre as missões que deveria cumprir, e mais raro ainda se identificam os fatores políticos externos nas trajetórias de desenvolvimento.

Possivelmente a perspectiva crítica mais fértil ao nacionalismo metodológico nos estudos sobre as trajetórias de desenvolvimento continua sendo o que nas formulações originais da Cepal dos anos 1950 se denominava de marco histórico estrutural. Para seus principais teóricos (como Raul Prebisch ou Celso Furtado) a inteligibilidade de uma dada trajetória nacional de desenvolvimento - em ampla divergência com as teorias sobre a modernização - não poderia ser apreendida sem explicitar a especificidade de sua inserção internacional e as dimensões econômicas e políticas historicamente construídas deste contexto. O dilema fundamental das economias periféricas era o de como deslocar através da mudança estrutural as restrições externas que tolhiam e condicionavam o seu desenvolvimento.

A abordagem centro-periferia recusava a limitar ou atribuir o sucesso ou fracasso do desenvolvimento às políticas e decisões definidas estritamente no espaço nacional. Afinal, a autonomia da nação e a força de seus fatores endógenos constituem uma dimensão essencial do próprio desenvolvimento e do poder do estado nacional e, consequentemente, não pode ser pressuposta. Nos anos 1960 e 1970 diversas versões da teoria da dependência ou análises desenvolvidas por autores de orientação marxista sobre o imperialismo, como Baran (1969) ou Wallerstein (1979), exploraram dimensões sociológicas e políticas das posições periféricas numa linha de argumentação metodologicamente distinta mas de algum modo próxima às análises cepalinas sobre a dicotomia centro-periferia. ${ }^{10}$

Nos anos 1970, o sucesso da industrialização em alguns países periféricos, num contexto internacional marcado pela ruptura do padrão monetário internacional erigido em Breton Woods e pela abundância de liquidez, desafiou as generalizações e simplificações excessivas de boa parte desta abordagem, sobretudo das teorias da dependência. Afinal, a periferia era formada por realidades muito distintas, e em alguns países como o Brasil, o México ou a Coréia, a industrialização havia atingido dimensões que ultrapassavam os limites atribuídos ao subdesenvolvimento. ${ }^{11}$ Ainda que o elevado peso das empresas multinacionais nos setores industriais dinâmicos destes países conferisse uma

(10) Para uma análise crítica das teorias da dependência ver Palma (2008).

(11) Hirschman (1982) criticou, com razão, o excessivo pessimismo que se abateu no continente sobre as possibilidades de prosseguimento da industrialização. 
especificidade a este tipo de desenvolvimento, a sua dinâmica deveria ser explicada essencialmente por fatores endógenos à nação.

Em um livro provocador publicado em 1980 - "Imperialismo, Pioneiro do Capitalismo" - o historiador marxista Bill Warren fazia uma forte crítica às análises marxistas da dependência centradas na existência de um permanente "surplus drain" na periferia e consequentemente num tolhimento permanente ao desenvolvimento econômico. Warren, numa linha que muito mais tarde será também abraçada por outros autores marxistas, defendia, ao contrário daquela abordagem, que o imperialismo, tal como na clássica análise de Marx sobre a colonização da Índia pela Inglaterra, não se baseava apenas na exploração, mas se constituía num instrumento da difusão do capitalismo e de suas forças produtivas entre as regiões atrasadas.

No Brasil, a crítica à Cepal e à teoria da dependência de uma perspectiva não ortodoxa foi desenvolvida pela escola de Campinas ${ }^{12}$ ao longo dos anos 1970 . Entre as diversas contribuições que esta escola deu para o estudo do desenvolvimento capitalista e para a revisão das análises históricas da economia brasileira e do seu capitalismo tardio afirmou-se um paradigma em que a dinâmica e os dilemas do desenvolvimento econômico brasileiro, devido às dimensões atingidas por suas forças produtivas - com a produção doméstica de bens de capital - resultavam essencialmente de seus determinantes endógenos. A internacionalização do seu mercado interno tornava endógenas as restrições externas examinadas nos estudos tradicionais da Cepal. ${ }^{13}$

O nacionalismo metodológico parecia ser afinal, consistente com uma realidade em que a abundância de liquidez internacional e grande endividamento externo haviam viabilizado diferentes respostas entre os países periféricos. Na América Latina, Brasil e México, através de suas indústrias, haviam diversificado suas economias e exportações, superando os limites de um padrão de acumulação dependente do setor exportador tradicional. Na Ásia, o mesmo havia ocorrido com a Coréia. Os assim denominados Newly Industrialized Countries (NICs), no jargão dos estudos internacionais do final dos anos 1970 sobre o desenvolvimento, apontavam para as transformações produtivas decorrentes de exitosas estratégias nacionais desenvolvimentistas.

A crise dos anos 1980, entretanto, revelou os limites do nacionalismo metodológico. O Brasil, a despeito de sua base produtiva foi, após a moratória mexicana, nivelado pelos bancos internacionais credores aos demais países endividados da América Latina, interrompendo o seu ciclo de expansão, percorrendo tal como a Bolívia ou a Argentina um caminho de estagnação e alta inflação. Nesta mesma década, países asiáticos tão distintos do ponto de vista produtivo mas altamente endividados, como, por exemplo, Coréia ou Indonésia, não tiveram maior descontinuidade em seu financiamento externo, prosseguindo em suas trajetórias de grande crescimento. Ásia e América Latina vivenciaram na década de 1980 experiências muito distintas. O tipo de inserção internacional e a "forma de agir do centro cíclico principal" (como em 1949 Prebisch observou sobre a passagem da liderança da Inglaterra para os EUA) sobre as diferentes

(12) Uma competente resenha nesta direção foi realizada por Rodrigues (2009).

(13) Uma análise sobre esta questão foi desenvolvida em Medeiros e Serrano (2001). 
regiões pareciam explicar aqui os diferentes resultados percorridos pelos países periféricos; estes dificilmente seriam inteligíveis se examinados exclusivamente a partir de suas dimensões nacionais. ${ }^{14}$

Possivelmente, o caminho percorrido na literatura não ortodoxa sobre o desenvolvimento - a passagem de uma ênfase nas dimensões externas para um excessivo endogenismo - se explique pela ausência, nos estudos pioneiros do desenvolvimento, incluindo aqui a Cepal, de uma análise sobre a moeda e sobre as dimensões financeiras autônomas da fragilidade externa. A formulação originária sobre polarização centroperiferia, tal como a desenvolvida por Prebisch, era centrada na especialização produtiva e as dimensões monetárias e financeiras exploradas em sugestivas análises se subordinavam e decorriam daquela situação estrutural. ${ }^{15}$ Posteriormente, no capitalismo ordenado de Bretton Woods, com as finanças internacionais subordinadas a controles domésticos por estados keynesianos nacionais, a afirmação de estratégias nacionais desenvolvimentistas em alguns países periféricos ampliava objetivamente a autonomia das decisões nacionais sobre as variáveis externas e o primado do capital produtivo sobre as finanças, reforçando análises centradas no "nacionalismo metodológico".

Os anos 1990, caracterizados pela difusão do neoliberalismo como projeto hegemônico acompanhado por sucessivas crises externas entre os países periféricos, reintroduziram a polarização centro-periferia em outras bases, com particular ênfase em suas dimensões patrimoniais e financeiras. E com elas as questões das hierarquias entre as moedas e do financiamento externo ganharam efetiva ênfase nos estudos do desenvolvimento, retomando a importância que sempre possuíram entre os historiadores econômicos, quer de inspiração marxista, quer keynesiana. ${ }^{16}$

O segundo aspecto crítico presente nas principais análises sobre o desenvolvimento (incluindo a tradição da Cepal) é a ausência de análises críticas sobre por que os Estados fazem ou não fazem o que normativamente as análises consideram que deva ser feito em prol do desenvolvimento. Trata-se aqui da complexa relação entre o poder econômico e o poder político. Embora o nacionalismo metodológico seja compatível tanto com as abordagens sobre o desenvolvimento centrado no estado quanto nas abordagens liberais (como as seguida nos estudos comparativos do Banco Mundial), ele é, por assim dizer, um suposto essencial do primeiro tipo de análise. Desse modo tal

(14) Para uma discussão nesta linha de argumentação ver Medeiros (1997), Palma (2005).

(15) Em Medeiros (2008) esta questão é examinada. Numa linha de argumentação semelhante sobre a análise de Celso Furtado ver Bastos (2008).

(16) Na América Latina e no Brasil em particular, desde o início dos anos 1980, no campo heterodoxo as análises concentraram-se excessivamente na macroeconomia de curto prazo, com algumas importantes exceções - como os ensaios de Furtado (1982) e Tavares (1985) - que buscavam dar conta dos novos dilemas do desenvolvimento em países periféricos. Posteriormente as reflexões macro estruturalistas sobre o desenvolvimento econômico vieram progressivamente se afirmando sobretudo nos anos 1990 como uma reação às reformas liberalizantes do Consenso de Washington. Nestas, afirmou-se um esforço de maior articulação das dimensões estruturais com as macroeconômicas, retornando a tradição original aberta por Prebisch. Nesta direção a influência dos estudos de Ffrench-Davis na Cepal e Ylmar Akyüz na Unctad foram importantes para a consolidação desta perspectiva nestas instituições. Uma contribuição recente nesta direção pode ser vista em Bresser Pereira (2010). 
Carlos Aguiar de Medeiros

abordagem requer uma dupla autonomia, a do Estado nacional frente às classes e do estado frente a outros estados.

O Estado nacional desenvolvimentista - tal como se depreende em boa parte das análises institucionalistas sobre as economias dinâmicas da Ásia (um amplo espectro iniciado com o influente estudo Chalmers Johnson sobre o Japão em 1982 e seguido por Alice Amsden, Robert Wade, Ha-Joon-Chang, Peter Evans e tantos outros) ${ }^{17}$ - é descrito como um ator e formulador autônomo em relação aos interesses econômicos constituídos e, assim como presente na tradição funcionalista weberiana, move-se por missões estabelecidas por uma burocracia meritocrática. Concebido como um ente em si, a questão central do desenvolvimento nestas análises foca-se na análise da capacitação e funcionalidade deste Estado. É a sua capacidade de controlar, policiar e disciplinar estes interesses que distingue as análises das trajetórias de desenvolvimento "centradas no Estado". Tendo em vista a decisiva importância de sua função enquanto coordenador dos investimentos, elaborador de estratégia e regulador dos conflitos, o sucesso do desenvolvimento é exatamente identificado com o da formação do Estado desenvolvimentista. Como na maioria dos países não existe tal Estado, o desenvolvimento permanece por assim dizer sendo um segredo, o da gênese e evolução deste Estado.

Um exemplo sugestivo sobre os limites desta abordagem pode-se depreender das narrativas sobre a crise do Estado desenvolvimentista ao longo dos anos 1990. Para Chang (2006) sob o peso dos interesses rentistas do capital financeiro e das pressões dos EUA, o Estado desenvolvimentista coreano desabou ao longo dos anos 1990. Mas, se de fato esta explicação da crise do Estado desenvolvimentista na Coréia é consistente, a análise sobre os anos 60 e 70 deveria considerar com mais ênfase a articulação dos grupos de interesses econômicos e políticos que sustentaram aquele Estado ao longo daquelas décadas. Tal esforço possivelmente iria identificar um Estado muito menos autônomo do que o que se depreende das narrativas institucionalistas (como a do próprio Chang) predominantes. ${ }^{18}$

Mas se existem importantes falhas nas abordagens sobre as estratégias desenvolvimentistas "Estado-centradas", fora deste campo interpretativo, as relações Estado e mercado não tiveram melhor capacidade explicativa sobre as trajetórias de desenvolvimento.

Na tradição liberal e pluralista que constitui parte do pensamento do mainstream como na Nova Economia Política, Escolha Pública - também o Estado tem uma importância central nas explanações sobre as trajetórias de desenvolvimento, não porque ele cumpre funções econômicas decisivas, tais como a coordenação dos investimentos como nos estudos sobre o Estado desenvolvimentista, mas porque ele tolhe ou cria direitos proprietários e modela comportamentos e incentivos que geram resultados econômicos produtivos ou improdutivos. De forma distinta da abordagem anterior, nesta abordagem a

(17) Para uma síntese ver Chang (2003).

(18) Esta linha foi seguida por Chibber (2003) que convincentemente argumenta que ao longo dos anos 1990 os Chaebols coreanos já não mais necessitavam do tipo de estado desenvolvimentista das décadas anteriores, este fora menos uma construção imposta de cima e mais uma instituição construída em ambas as direções. 
análise sobre o Estado é muito mais enraizada na sociedade e nas instituições. O Estado, entendido aqui como governo, representa interesses de grupos e apenas quando há uma livre circulação do poder político, o desenvolvimento econômico, entendido como resultado da expansão das trocas privadas, ocorre de forma desimpedida. O segredo aqui é o da formação da sociedade liberal e o de seu triunfo sobre outras formas de estruturação e representação dos interesses. ${ }^{19}$

A incapacidade desta perspectiva em capturar as transformações contemporâneas sobre o crescimento e as crises de desenvolvimento pode ser evidenciada na mudança de posição do mainstream sobre o desenvolvimento asiático: as mesmas economias descritas nos diversos documentos do Banco Mundial como "amigáveis ao mercado" tornaram-se depois da crise de 1997 exemplos de um "capitalismo de compadres".

No campo marxista, em que o Estado capitalista é pensado como uma relação social voltada a promover os interesses de longo prazo dos capitalistas, as relações que condicionam o poder político e estratégico do Estado foram desenvolvidas em diversas contribuições com maior ou menor complexidade (como as análises regulacionistas, tais como as desenvolvida por Robert Boyer, ou de seus similares americanos sobre as estruturas sociais de acumulação, bem como em estudos de tradição gramsciana). ${ }^{20}$ Nestas análises, a capacidade de ação do Estado não é independente do poder político dos grupos econômicos dominantes na construção de suas estratégias de poder. Estas análises, entretanto, a despeito de ricas sugestões conceituais sobre a organização dos interesses nas sociedades capitalistas avançadas e sobre o maior ou menor predomínio da acumulação privada de capitais sobre outros valores e objetivos sociais, tiveram relativamente pouca influência sobre as análises concretas das trajetórias de desenvolvimento. ${ }^{21}$

Como se pode depreender de um exame crítico destas abordagens opostas, há uma questão de fundo não satisfatoriamente desenvolvida, que diz respeito a uma clássica questão da sociologia e da economia política sobre a relação entre interesses materiais, classes sociais e o poder político nas trajetórias de desenvolvimento econômico.

A incorporação destas questões nos estudos de desenvolvimento é evidentemente muito complexa. Um terreno prudente é a busca de explanações e narrativas históricas que apontem aqui e ali como se formou em determinado país uma coalizão de interesses favoráveis a determinada estratégia econômica e como foi possível obter um grau satisfatório de coesão social. E mais exatamente é importante examinar como a coalizão de interesses formada foi compatível com o desenvolvimento da nação.

(19) Autores como Acemoglu, Johnson, Robinson, (2005) buscaram identificar nos processos econômicos coalizões de interesses de grupos a favor de determinadas estratégias identificando o triunfo de uma determinada política ao poder político das coalizões construídas tanto plano interno quanto no externo.

(20) Para uma discussão ver Jessop (2002).

(21) Novamente a forma como as análises sociológicas marxistas foram incorporadas mecanicamente na teoria da dependência pode ter contribuído para a sua marginalização nas análises sobre as trajetórias de desenvolvimento. Certamente que nas narrativas nacionais sobre a estruturação dos interesses e sua influencia sobre as estratégias nacionais de desenvolvimento encontram-se um grande número de estudos que seguem esta abordagem, entretanto são escassos os trabalhos que incluem estas relações nas análises mais amplas das estratégias de desenvolvimento. Hirschman (1982), Gereffi (1990) são sugestivas exceções. 
Carlos Aguiar de Medeiros

Como se observou no exame das relações entre o Estado, o poder político e o mercado, esta análise não pode se limitar a um nacionalismo metodológico, sobretudo a partir dos amplos transbordamentos dos fluxos de comércio, investimento e finanças que se afirmaram nas últimas décadas, alterando os mercados e as articulações de interesses dos grupos econômicos. Não existe apenas uma relação de mão dupla entre o Estado e as classes sociais e grupos de interesses no país, que limita e condiciona as estratégias de desenvolvimento, mas também uma relação política entre Estados territoriais, o que leva, nos exames sobre as trajetórias nacionais de desenvolvimento, a um necessário diálogo com as questões examinadas na economia política internacional.

\section{Referências bibliográficas}

ACEMOGLU, D.; JOHNSON, S.; ROBINSON, J Institutions as the fundamental cause of long-run growth. In: AGHION, P.; DURLAUF, S. (Ed.). Handbook of economic growth. Elsevier, 2005.

AGARWALA, A.; SINGH, S. P. A economia do subdesenvolvimento. Rio de Janeiro: Forense, 1969.

BARAN, P. Economia política do subdesenvolvimento. In: AGARWALA, A.; SINGH, S. P. A economia do subdesenvolvimento. Rio de Janeiro: Forense, 1969.

BASTOS, P. P. Zahluth. Centro e periferia no padrão ouro libra: Celso Furtado subestimou a dinâmica da dependência financeira? Campinas, SP: Unicamp. IE, 2008. (Texto para Discussão, n. 138).

BRESSER PEREIRA, L. C. Globalização e competição. Campus, Elsevier, 2010.

CHANG, H Joon. Hamlet without the Prince of Dennmark: how development has disappeared from today' development discourse". Forthcoming in: KHAN, S.; CHRISTIANSEN, J. (Ed.). Towards new developmentalism: market as means rather than master. Routledge (Abingdon), 2009.

CHANG, Ha-Joon (Ed.). Rethinking development economics. London: Anthem Press, 2003.

(Ed.). Institutional change and economic development. Anthem Press, United Nations University Press, 2007.

. The East Asian development experience. Zed Books, 2007.

CHIBBER, V. Locked in place. Princenton University Press, 2003.

FURTADO, C. A nova dependencia, divida externa e monetarismo. Rio de Janeiro: Paz e Terra, 1982.

GEREFFI, G. Paths of industrialization. In: GEREFFI, Gary; WYMAN, Donald. Manufacturing miracles. New Jersey: Princeton University Press, 1990.

GORE, C. Methodological nationalism and the misunderstanding of east Asian industrialization. European Journal of Development Research, v. 8, n. 1, 1996.

HIRSCHMAN, A. The political economy of import substitution industrialization in Latin America. The Quarterly Journal of Economics, v. 82, n. 1, 1982. 
JESSOP, B. The future of the capitalist state. UK: Polity, 2002.

MEDEIROS, C. Financial dependency and growth cycles in Latin American countries. JPKE, v. 31, n. 1, 2008.

Globalização e a inserção internacional diferenciada da Ásia e da América Latina. In: TAVARES, Maria da Conceição; FIORI, José Luís. Poder e dinheiro. Rio de Janeiro: Vozes, 1997.

; SERRANO, F. Inserção externa, exportações e crescimento no Brasil. In: FIORI, José Luís; MEDEIROS, Carlos (Org.). Polarização mundial e crescimento. Rio de Janeiro: Vozes, 2001.

NORTH, D. C. Institutions, institutional change and economic performance. Cambridge University Press, 1990.

PALMA, G. Gansos voadores e patos vulneráveis: a diferença da liderança do Japão e dos EUA, no desenvolvimento do Sudeste Asiático e da América Latina. In: FIORI, J. L. (Org.). O poder americano. Rio de Janeiro: Vozes, 2005.

Theories of dependency. In: DUTT, A.; ROS, J. International handbook of development economics. Edward Elgar, Northampton, EUA, 2008.

PASINETTI, L. Keynes and the Cambridge Keynesians. Federico Caffé Lectures, Cambridge University Press, 2007.

RODRIGUES, O. El estructuralismo latinoamericano. Siglo XXI, 2007.

ROS, J. Development theory \& the economics of growth. Michigan, 2001.

TAVARES, M. C. (1985). A retomada da hegemonia americana. In: TAVARES, M. C.; FIORI, J. L. Poder e dinheiro - Uma economia política da globalização. Rio de Janeiro: Vozes, 1997.

WALLERSTEIN, I. The capitalist world economy. Cambridge University Press, 1979.

WARREN, B. Imperialism, pioneer of capitalism/Edited by John Sender. Verso, 1980. 